\title{
Cloning, expression, sequence analysis and biochemical characterization of an autolytic amidase of Bacillus subtilis 168 trpC2
}

\author{
SIMON J. Foster \\ Department of Molecular Biology and Biotechnology, PO Box 594, Firth Court, Western Bank, University of Sheffield, \\ Sheffield S10 2UH, UK
}

(Received 17 December 1990; revised 19 March 1991; accepted 24 April 1991)

\begin{abstract}
By use of a functional assay for activity, an autolysin structural gene was cloned on a $3 \mathrm{~kb}$ EcoRI DNA fragment from a $\lambda$ gt11 expression library of Bacillus subtilis $168 \mathrm{trp} C 2$ genomic DNA. Sequencing of the fragment showed five open reading frames, the central one of which encoded the lytic enzyme as found by subclone activity mapping and its homology to a recently sequenced autolysin gene. The protein had a deduced sequence of 272 amino acids and a molecular mass of 29957 Da. When expressed in Escherichia coli DH5 $\alpha$, the protein was processed to a $21 \mathrm{kDa}$ form, as estimated by renaturing SDS-PAGE. The autolysin was an $\mathrm{N}$-acetylmuramyl-L-alanine amidase and its activity was $\mathrm{MgCl}_{2}$-dependent (20 mM optimum) and LiCl-sensitive. The enzyme could bind to and hydrolyse a wide range of peptidoglycan substrates isolated from Gram-positive bacteria; the binding was also $\mathrm{MgCl}_{2}$-dependent. Initial mapping experiments located the autolysin gene near aroD on the $B$. subtilis 168 chromosome.
\end{abstract}

\section{Introduction}

Bacterial autolysins are potentially lethal enzymes capable of hydrolysing peptidoglycan, the major component of bacterial cell walls. The enzymes are characterized in vitro by their hydrolytic bond specificity as $\mathrm{N}$-acetylmuramidases (muramidases), $\mathrm{N}$-acetylglucosaminidases (glucosaminidases), $\mathrm{N}$-acetylmuramylL-alanine amidases (amidases), endopeptidases and transglycosylases (Ghuysen et al., 1966). Autolysins have been implicated in several important cellular functions, including cell wall growth and turnover, cell separation, flagellation, competence, differentiation and the lytic action of antibiotics (Pooley \& Karamata, 1984; Ward \& Williamson, 1984). The involvement of specific $B$. subtilis 168 autolysins in all of the above processes is speculative, as they have not been thoroughly investigated at the molecular level. B. subtilis 168 has two major vegetative cell autolysins, an amidase and a glucosaminidase of 50 and $90 \mathrm{kDa}$ respectively, and of as yet

This paper is dedicated to the memory of Professor Howard Rogers, whose help and encouragement were much appreciated, and who will be sorely missed.

Abbreviations: FDNB, 2,4-dinitrofluorobenzene; ORF, open reading frame.

The nucleotide sequence data reported in this paper have been submitted to GenBank and have been assigned the accession number M59232. unknown function (Herbold \& Glaser, 1975; Rogers et al., 1984).

Direct cloning techniques, combined with a functional assay system, have resulted in the isolation of autolysin structural genes in E. coli. By the use of these methods, the structural genes for a $23 \mathrm{kDa}$ amidase and an $80 \mathrm{kDa}$ glucosaminidase from Staphylococcus aureus (Biavasco et al., 1988; Jayaswal et al., 1990) and a $27 \mathrm{kDa}$ autolysin of unknown specificity from a Bacillus sp. have been isolated (Potvin et al., 1988). This paper reports the isolation, sequence analysis and mapping of a gene encoding a low-molecular-mass autolysin of $B$. subtilis $168 \operatorname{trp} C 2$. The mode of action and initial biochemical characterization of the cloned enzyme are also described.

\section{Methods}

Bacterial strains and growth conditions. Bacillus subtilis 168 trpC2 (Rogers et al., 1984) and Bacillus megaterium KM (Stewart et al., 1981) were grown routinely in Penassay broth (Difco) at $37^{\circ} \mathrm{C}$ and $30^{\circ} \mathrm{C}$ respectively. Micrococcus luteus ATCC 4698 (Sigma), Escherichia coli ER1458 (New England Biolabs) and DH5 (Hanahan, 1983; BRL) were grown in Luria-Bertani medium (LB) at $37^{\circ} \mathrm{C}$. B. megaterium KM endospores were prepared and stored as described by Stewart et al. (1981).

Preparation of purified cell wall substrates. Mid-exponential $\left(\mathrm{OD}_{600}=0.6\right)$ cultures or purified spores were broken, and cell walls were prepared and stored at $-20^{\circ} \mathrm{C}$ as described by Johnstone \& Ellar 
(1982). Purified vegetative cell walls of Bacillus sphaericus 9602 and Lactobacillus arabinosus NCIB 6376 were a gift from Dr P. J. White, University of Sheffield, UK. Procion-Red-labelled walls were produced using a method based on that of Forsberg \& Rogers (1971). Purified B. subtilis 168 vegetative cell walls were suspended at $10 \mathrm{mg} \mathrm{ml}^{-1}$ in $2 \%(\mathrm{w} / \mathrm{v}) \mathrm{NaCl}$. After $30 \mathrm{~min}$ at $60^{\circ} \mathrm{C}$ with constant shaking $\mathrm{NaOH}$ and Procion Red MX5B (ICI) were added to a final concentration of $0.1 \mathrm{M}$ and $10 \mathrm{mg} \mathrm{m}^{-1}$ respectively. After incubation with shaking at $60^{\circ} \mathrm{C}$ for $3 \mathrm{~d}$, walls were washed six times with distilled water and stored at $-20^{\circ} \mathrm{C}$.

Identification of a Bacillus subtilis 168 autolysin structural gene. A $\lambda$ gt 11 library containing a partial EcoRI digest of B. subtilis 168 trpC2 genomic DNA (gift from Dr C. Price, University of California, Davis, USA) was used to screen for autolysin activity. E. coli ER1458 was infected with phage and plated onto $\mathrm{LBMg}^{2+}\left(10 \mathrm{mM}-\mathrm{MgSO}_{4}\right)$ plates (Huynh et al., 1985). The phage overlay contained $1 \mathrm{~mm}$-isopropyl $\beta$-D-thiogalactopyranoside (IPTG) and $0.66 \mathrm{mg} \mathrm{ml}^{-1}$ Procion-Redlabelled walls. After incubation at $37^{\circ} \mathrm{C}$ overnight, autolysinproducing clones were identified by a zone of clearing in the red background around the plaque. The autolysin-producing clones were purified and amplified, and phage DNA was isolated. The insert was characterized by EcoRI digestion (Huynh et al., 1985).

Subcloning and DNA sequencing of an autolysin-encoding DNA region. A $3 \mathrm{~kb} E c o \mathrm{RI} \lambda \mathrm{gt} 11$ insert was subcloned into the EcoRI site of plasmid pUBS1, a pUC19-based vector (from Dr G. Murphy, Institute of Plant Science Research, Cambridge, UK), to give pSFP100. This plasmid was transformed into $E$. coli DH $5 \alpha$. A set of nested deletion subclones were prepared for sequencing by timed exonuclease digeston (Henikoff, 1984: Promega, Erase-a-Base). The total DNA sequence of the $3 \mathrm{~kb}$ insert was determined on both strands using the dideoxy-chain termination method (Sanger, 1977) with modified T7 polymerase (Sequenase, USB).

Expression of the cloned B. subtilis 168 autolysin in E. coli DH5 $\alpha$. The ability of $E$. coli DH $5 \alpha$ with plasmid pSFP100, or subclones thereof, to express the $B$. subtilis 168 autolysin was tested using a plate assay. Clones were patched onto LBAmp $\left(50 \mu \mathrm{g}\right.$ ampicillin $\left.\mathrm{ml}^{-1}\right)$ agar with a $3 \mathrm{ml}$ overlay of LBAmp agar containing $0.66 \mathrm{mg} \mathrm{ml}^{-1}$ Procion-Redlabelled $B$. subtilis cell walls. After overnight growth at $37^{\circ} \mathrm{C}$, the cells were lysed over chloroform $\left(20 \mathrm{~min}, 20^{\circ} \mathrm{C}\right)$ and incubated for a further $24 \mathrm{~h}$. The clones expressing autolysin were identified by a zone of clearing around the colony.

Initial mapping of the autolysin gene on the B. subtilis chromosome. The autolysin gene was insertionally inactivated by ligation of a $1.3 \mathrm{~kb} S \mathrm{maI}$ fragment from pMI1 101, containing a chloramphenicol acetyl transferase (cat) gene (Youngman et al., 1984; gift from Dr L. Zheng, Biological Laboratories, Harvard University, Cambridge, USA), into $N d e$ I-cut, blunt-ended and phosphatased pSFP100. The unique $N d e I$ site in pSFP100 occurs within the autolysin coding region. Chloramphenicol-resistant $\left(3 \mu \mathrm{g} \mathrm{ml}^{-1}\right)$ clones of $B$. subtilis $168 \mathrm{SF} 1$ were recovered after transformation (Anagnostopoulos \& Spizizen, 1961) with the cat-containing construct, linearized with PstI. The location of the autolysin gene on the $B$. subtilis chromosome was determined by PBS1 transduction (Dubnau et al., 1967), using the mapping kit of Dedonder et al. (1977).

Preparation of autolysin-containing extract. E. coli $\mathrm{DH} 5 \alpha$, with plasmids pUBS1 or pSFP102 (see Fig. 1) were grown overnight in $200 \mathrm{ml} \mathrm{LBAmp}\left(50 \mu \mathrm{g} \mathrm{ml}^{-1}\right)$. Cells were harvested $(6000 \mathrm{~g}, 10 \mathrm{~min}$, $\left.4{ }^{\circ} \mathrm{C}\right)$, the pellet $(0.7 \mathrm{~g}$ wet wt) was washed with $50 \mathrm{mM}$-Tris $/ \mathrm{HCl}$, $\mathrm{pH} 7.5$, at $4{ }^{\circ} \mathrm{C}$, and disrupted by sonication $(6 \times 30 \mathrm{~s}$ bursts, full power; Soniprep 150, MSE Instruments) in $10 \mathrm{ml} 50 \mathrm{~mm}-\mathrm{Tris} / \mathrm{HCl}$, pH 7.5, $10 \mathrm{~mm}-\mathrm{MgCl}_{2}, 250 \mathrm{mM}-\mathrm{LiCl}$ and $0.5 \mathrm{~mm}$-PMSF. Greater than $90 \%$ of cells were broken by this method. Unbroken cells and insoluble cell debris was removed by centrifugation $\left(18000 \mathrm{~g}, 5 \mathrm{~min}, 4^{\circ} \mathrm{C}\right)$ and the supernatant used directly as a source of enzyme.

Assay for autolysin activity. Lytic activity was measured by the ability of the crude enzyme preparation to decrease the optical density of a suspension of mid-exponential vegetative cells, or purified cell walls, at $37^{\circ} \mathrm{C}$. Unless otherwise stated, the reaction contained $1 \mathrm{ml}$ of walls/ cells suspended to a final $\mathrm{OD}_{450}$ of $0 \cdot 2$, in $25 \mathrm{mM}-\mathrm{Tris} / \mathrm{HCl}, \mathrm{pH} 7.5$, with $20 \mathrm{mM}-\mathrm{MgCl}_{2}$. Each assay was carried out in duplicate and 1 unit of enzyme activity (U) was defined as the amount of enzyme necessary to decrease the $\mathrm{OD}_{450}$ by $0.001 \mathrm{~min}^{-1}$.

Assay for autolysin activity in renatured SDS-PAGE gels. SDS-PAGE $(11 \%, \mathrm{w} / \mathrm{v}$, acrylamide) gels containing $0.1 \%(\mathrm{w} / \mathrm{v})$ purified $B$. subtilis vegetative cell walls were used for detection of lytic activity (Jayaswal et al, 1990). Following electrophoresis, gels were rinsed in distilled water and then renatured in $1 \%(\mathrm{v} / \mathrm{v})$ Triton X-100 (Aldrich), $20 \mathrm{~mm}$ $\mathrm{MgCl}_{2}, 25 \mathrm{~mm}$-Tris $/ \mathrm{HCl}, \mathrm{pH} 7 \cdot 5,\left(3 \times 30 \mathrm{~min}, 20^{\circ} \mathrm{C}\right)$. Gels were then incubated for $16 \mathrm{~h}$ at $37^{\circ} \mathrm{C}$ in the same buffer but containing only $0.1 \%$ $(\mathrm{v} / \mathrm{v})$ Triton $\mathrm{X}-100$. Autolysin activity appeared as a zone of clearing in the translucent background. This was enhanced by staining the gel with $0.1 \%(\mathrm{w} / \mathrm{v})$ methylene blue in $0.01 \%(\mathrm{w} / \mathrm{v}) \mathrm{KOH}$ prior to photography (Jayaswal et al., 1990).

Characterization of the cloned autolysin. To determine the hydrolytic bond specificity of the cloned autolysin, purified B. subtilis 168 vegetative cell walls were suspended at $5 \mathrm{mg} \mathrm{ml}^{-1}$ in $5 \mathrm{ml} 20 \mathrm{~mm}$ $\mathrm{MgCl}_{2}$. Cell extract $(25 \mu \mathrm{l})$ from $E$. coli DH5 $\alpha$ with either pUBS1 or pSFP102 was added and the mixture was incubated at $37^{\circ} \mathrm{C}$. Samples $(0.5 \mathrm{ml})$ were withdrawn at intervals and boiled for $10 \mathrm{~min}$. Following removal of undigested walls by centrifugation $(14000 \mathrm{~g}, 10 \mathrm{~min})$, samples were assayed for an increase in reducing groups (Thompson \& Shockman, 1968) and amino termini (Ghuysen et al., 1966). To determine to which alanine isomer the new amino termini could be attributed, the method of Margot, et al. (1991) was used. Walls labelled exclusively at the L-alanine residue were prepared by the use of a D-alanine racemase (dal) mutant strain $[B$. subtilis 168 IA4 aroI906 dal-1 purE1 trpC2 (BGSC)]. Strain IA4 showed a reversion frequency of $<1 \times 10^{-4}$ to $\mathrm{dal}^{+}$under the conditions used. This strain was grown to mid-exponential phase $\left(\mathrm{OD}_{600}=0.6\right)$ in a medium containing both unlabelled $\mathrm{D}$-alanine and $\mathrm{L}-\left[{ }^{14} \mathrm{C}\right]$ alanine (Amersham, $155 \mathrm{mCi}$ $\left.\mathrm{mmol}^{-1}, 5.74 \mathrm{GBq} \mathrm{mmol}^{-1}\right)$. Vegetative cell walls were prepared as described above, digested with the enzyme extract, treated with 2,4-dinitrofluorobenzene (FDNB), and acid-hydrolysed. The amino acids were separated by TLC. The radioactivity in the various TLC spots was determined by scraping the silica gel off the TLC plate, and counting its radioactivity in a Beckman LS 1801 scintillation counter.

\section{Results}

\section{Isolation of an autolysin-encoding gene from B. subtilis 168}

From approximately 120000 p.f.u. of an EcoRI $B$. subtilis 168 genomic DNA library in $\lambda \mathrm{gt} 11,27$ plaques were identified as producing zones of clearing on agar plates containing Procion-Red-labelled walls of B. subtilis 168 . The putative phage clones were purified by replating at a lower titre (200 p.f.u. per plate). The B. subtilis 168 DNA inserts were isolated from six purified $\lambda$ gt 11 clones and found in all cases to be approximately $3 \mathrm{~kb}$ in size. When 


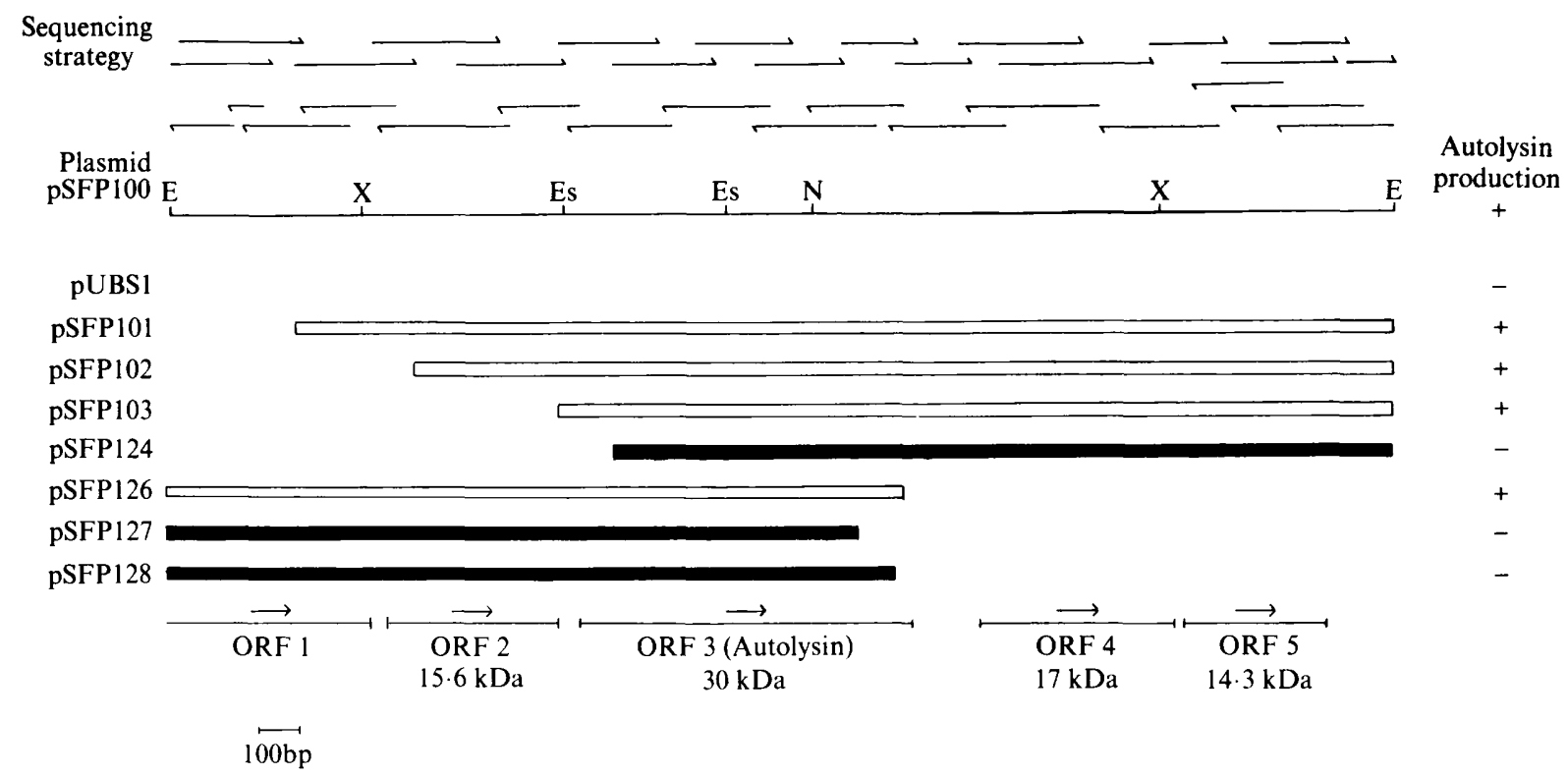

Fig. 1. Restriction map, sequencing strategy, subclone activity mapping and ORF positions of the 3003 bp pSFP100 insert. Each sequencing strategy arrow shows the length and direction of a sequence determination. The ability of various subclones to express activity is shown, as is the position and direction of coding of the five ORFs. The size of the predicted proteins from the complete ORFs is indicated. The restriction map uses the following abbreviations: E, EcoRI; Es, EspI; N, NdeI; X, XmnI.

this $3 \mathrm{~kb}$ fragment was subcloned into pUBS1 to create pSFP100 and then transformed into $E$. coli $\mathrm{DH} 5 \alpha$, zones of clearing were observed around the colonies on agar containing Procion-Red-labelled walls. E. coli DH5 $\alpha$ alone, or with pUBS1, showed no zone of clearing. The hydrolysis of $B$. subtilis 168 walls was not IPTGdependent in $\lambda \mathrm{gt} 11$ containing the $3 \mathrm{~kb}$ insert or in $E$. coli DH5 $\alpha($ pSFP100).

$D N A$ sequence of the $3 \mathrm{~kb} B$. subtilis $168 \mathrm{DNA}$ fragment and identification of the autolysin-encoding gene

A set of nested deletion subclones was prepared for DNA sequencing. The autolysin-encoding gene was mapped to the central region of the $3 \mathrm{~kb}$ insert, according to the ability of the subclones to express lytic enzyme (Fig. 1). Subclone pSFP102 showed the most activity as measured empirically by the plate assay. The DNA sequence of the $3 \mathrm{~kb}$ fragment was determined on both strands (Fig. 2) using the strategy shown in Fig. 1. The region has five open reading frames (ORFs) all transcribed in the same direction (Figs 1 and 2). The ORF at the beginning of the cloned DNA is N-terminally truncated. The central ORF (ORF 3) was identified as the autolysin-encoding gene by the subclone mapping (Fig. 1) and by its striking homology to a previously sequenced autolysin gene from a Bacillus sp. (Potvin et al., 1988). The B. subtilis 168 autolysin is a protein of 272 amino acids and $29957 \mathrm{Da}$. The protein has $46.6 \%$ sequence identity over its $\mathrm{N}$-terminal 202 amino acids with the Bacillus sp. autolysin described by Potvin et al. (1988).

The autolysin gene is preceded by a putative ribosome binding site at bases 996-1003 (Fig. 2) with an estimated free energy for the Shine-Dalgarno interaction of $-11 \mathrm{kcal} \mathrm{mol}^{-1}\left(-46 \mathrm{~kJ} \mathrm{~mol}^{-1}\right)$ (Tinoco et al., 1973). Also, a putative rho-independent terminator with an estimated free energy for the stemloop structure of $-17 \mathrm{kcal} \mathrm{mol}^{-1}\left(-71 \mathrm{~kJ} \mathrm{~mol}^{-1}\right)$ (Tinoco et al., 1973), is present downstream from the autolysin stop codon at bases 1839-1867. Possible $\sigma^{\mathrm{A}}$-dependent promoter sequences are present upstream of the autolysin gene ( -35 and -10 at bases $916-921$ and 939-944, respectively). ORFs 1, 2, 4 and 5 show no significant homology to any known protein at present in the sequence database (OWL cumulative database, University of Leeds, UK, accessed by the SERC Daresbury facility).

\section{Mapping of the autolysin gene on the B. subtilis chromosome}

The autolysin gene, with introduced cat cassette, was mapped by PBS1 transduction and found to be $77 \%$ cotransduced with aroD (226 ; Piggot, 1989$)$ and $16 \%$ with leuB (247 ${ }^{\circ}$; Piggot, 1989). 
Fig. 2 (following pages). Nucleotide sequence of the cloned B. subtilis 168 autolysin region. Only the non-coding DNA strand is shown. The numbering of nucleotides is shown below the sequence, and the deduced amino acid sequence above. Arrows above the amino acid sequence denote the start of ORFs and asterisks denote stop codons. The putative ribosome binding site (RBS) and rho-independent terminator before and after the autolysin gene are also shown as lines above the sequence.

ORF 1

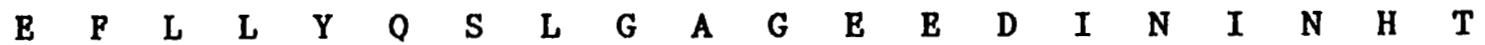
GAATTCTTACTTTACCAGTCATTGGGCGCAGGTGAAGAGGATATAAACATTAACCATACT 10 20 30 40 50

$\begin{array}{llllllllllllllllllll}\mathbf{V} & \mathbf{P} & \mathbf{I} & \mathbf{T} & \mathbf{A} & \mathbf{V} & \mathbf{A} & \mathbf{P} & \mathbf{P} & \mathbf{S} & \mathbf{V} & \mathbf{Q} & \mathbf{L} & \mathbf{D} & \mathbf{K} & \mathbf{S} & \mathbf{G} & \mathbf{L} & \mathbf{T} & \mathbf{N}\end{array}$ GTTCCTATTACAGCAGTTGCTCCGTTCTCAGTCCAGTTAGATAAAAGCGGGTTAACTAAT 70 80 90 100

110

120

$\begin{array}{llllllllllllllllllll}\mathbf{D} & \mathbf{G} & \mathbf{R} & \mathrm{L} & \mathrm{K} & \mathbf{V} & \mathbf{O} & \mathbf{T} & \mathbf{E} & \mathbf{G} & \mathbf{L} & \mathbf{N} & \mathbf{L} & \mathbf{S} & \mathbf{S} & \mathbf{L} & \mathbf{D} & \mathbf{T} & \mathbf{Q} & \mathbf{S}\end{array}$ GATGGTCGTTTAAAAGTTCAAACTGAAGGCTTGAATCTTAGCTCATTAGACACTCAATCA 130 140 150

160

170

180

$\begin{array}{lllllllllllllllllllll}K & \mathbf{T} & \mathbf{M} & \mathbf{D} & \mathbf{I} & \mathbf{V} & \mathbf{F} & \mathbf{H} & \mathbf{D} & \mathbf{K} & \mathbf{T} & \mathbf{B} & \mathbf{T} & \mathbf{I} & \mathbf{G} & \mathbf{B} & \mathbf{G} & \mathbf{N} & \mathbf{P} & \mathbf{P}\end{array}$ AAAACAATGGATATTGTCTTTCACGATAAAACAGAAACCATAGGTGAGGGTAACCCATTC 190 200

210

220

230

240

$\begin{array}{llllllllllllllllllll}\mathbf{T} & \mathbf{V} & \mathbf{G} & \mathbf{S} & \mathbf{F} & \mathbf{K} & \mathbf{T} & \mathbf{L} & \mathbf{L} & \mathbf{I} & \mathbf{E} & \mathbf{V} & \mathbf{Y} & \mathbf{G} & \mathbf{T} & \mathbf{A} & \mathbf{E} & \mathbf{T} & \mathbf{S} & \mathbf{E}\end{array}$ ACCGTTGGATCATTCAAAACGTTGCTCATTGAGGTTTATGGGACGGCTGAGACAAGTGAA $\begin{array}{lllll}250 & 260 & 270 & 280 & 290\end{array}$

$\begin{array}{llllllllllllllllllll}L & K & \mathbf{P} & \text { W } & \mathbf{G} & \mathbf{K} & \mathbf{S} & \mathrm{L} & \mathbf{S} & \mathbf{G} & \mathbf{T} & \mathbf{K} & \mathbf{R} & \mathbf{A} & \mathbf{L} & \mathbf{R} & \mathbf{G} & \mathbf{Q} & \mathbf{K} & \mathbf{V}\end{array}$ TTGAAGTTCTGGGGTAAATCCTTATCGGGAACAAAAAGAGCCCTTAGAGGGCAGAAAGTG

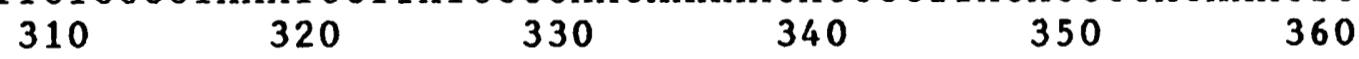

$\begin{array}{llllllllllllllllllll}D & D & G & T & \mathbf{P} & A & \mathbf{T} & \mathbf{S} & \mathbf{T} & \mathrm{K} & \mathbf{G} & \mathrm{K} & \mathbf{S} & \mathbf{E} & \mathbf{A} & \mathbf{W} & \mathbf{S} & \mathbf{P} & \mathbf{S} & \mathbf{I}\end{array}$ GATGACGGAACGTTTGCCACTAGCACAAAAGGAAAATCAGAAGCTTGGTCTTTTAGCATT 370 380 390 400 410 420

$\begin{array}{llllllllllllllllllll}\mathbf{T} & \mathbf{G} & \mathbf{P} & \mathbf{K} & \mathbf{E} & \mathbf{I} & \mathbf{V} & \mathbf{M} & \mathbf{E} & \mathbf{L} & \mathbf{T} & \mathbf{A} & \mathbf{L} & \mathbf{T} & \mathbf{N} & \mathbf{G} & \mathbf{N} & \mathbf{F} & \mathbf{S} & \mathbf{V}\end{array}$ ACTGGCTTTAAAGAAATTGTTATGGAGCTTACAGCTTTAACAAATGGAAACTTTTCAGTT

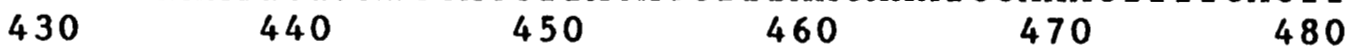

$\begin{array}{lllllll}R & G & T & A & V & S & *\end{array}$ AGAGGGACGGCCGTCTCATAAGATCCGGCTGTCCTTTTTTATTTGCCTCGGAGGAGGTGA 490 500 510 520 530 540

\section{ORF 2}

$\begin{array}{lllllllllllllllllll}M & \mathbf{E} & \mathbf{E} & \mathrm{T} & \mathbf{S} & \mathrm{L} & \mathbf{P} & \mathbf{I} & \mathbf{N} & \mathbf{P} & \mathbf{E} & \mathbf{T} & \mathbf{L} & \mathbf{D} & \mathbf{L} & \mathbf{A} & \mathbf{R} & \mathbf{V} & \mathbf{Y}\end{array}$ TTAGAATGGAGGAGACAAGTTTGTTTATCAATTTTGAAACATAGATTTAGCAAGAGTAT 550 560 570 580 590

600

$\begin{array}{llllllllllllllllllll}\mathbf{L} & \mathbf{P} & \mathbf{G} & \mathbf{G} & \mathbf{V} & \mathrm{K} & \mathbf{Y} & \mathbf{L} & \mathbf{D} & \mathbf{L} & \mathbf{L} & \mathbf{L} & \mathbf{V} & \mathbf{L} & \mathbf{S} & \mathbf{I} & \mathbf{I} & \mathbf{D} & \mathbf{V} & \mathbf{L}\end{array}$ ATTTATTTGGAGGGGTGAAGTACCTTGATTTACTTCTAGTACTTAGCATAATTGACGTTT 610 620 
$\begin{array}{llllllllllllllllllll}T & \mathbf{G} & \mathbf{V} & \mathbf{I} & \mathbf{K} & \mathbf{A} & \mathbf{W} & \mathbf{K} & \mathbf{F} & \mathbf{K} & \mathbf{K} & \mathbf{L} & \mathbf{R} & \mathbf{S} & \mathbf{R} & \mathbf{S} & \mathbf{A} & \mathbf{W} & \mathbf{P} & \mathbf{G}\end{array}$ TAACAGGAGTAATCAAGGCATGGAAATTCAAAAAACTGCGAAGTCGAAGCGCATGGTTTG $\begin{array}{llllll}670 & 680 & 690 & 700 & 710 & 720\end{array}$

$\begin{array}{llllllllllllllllllll}\mathbf{Y} & \mathbf{V} & \mathbf{R} & \mathrm{K} & \mathrm{L} & \mathbf{L} & \mathbf{N} & \mathbf{P} & \mathbf{F} & \mathbf{A} & \mathbf{V} & \mathbf{I} & \mathbf{L} & \mathbf{A} & \mathbf{N} & \mathbf{V} & \mathbf{I} & \mathbf{D} & \mathbf{T} & \mathbf{V}\end{array}$ GCTATGTCCGCAAGCTACTCAATTTCTTTGCGGTCATTTTAGCAAACGTGATTGATACAG $\begin{array}{llllll}730 & 740 & 750 & 760 & 770 & 780\end{array}$

$\begin{array}{llllllllllllllllllll}\text { L } & \mathbf{N} & \mathrm{L} & \mathbf{N} & \mathbf{G} & \mathbf{V} & \mathbf{L} & \mathbf{T} & \mathbf{P} & \mathbf{G} & \mathbf{T} & \mathbf{V} & \mathbf{L} & \mathbf{P} & \mathbf{Y} & \mathbf{I} & \mathbf{A} & \mathbf{N} & \mathbf{E} & \mathbf{G}\end{array}$ TACTCAATTTGAACGGTGTCTTAACCTTTGGTACCGTTCTTTTTTATATCGCTAATGAAG $\begin{array}{llllll}790 & 800 & 810 & 820 & 830 & 840\end{array}$

$\begin{array}{llllllllllllllllllll}\text { L } & \text { S } & \text { I } & \text { T } & \text { E } & \text { N } & \text { L } & \text { A } & \mathbf{Q} & \text { I } & G & \text { V } & \text { K } & \text { I } & \text { P } & \text { S } & \text { S } & \text { I } & \text { T } & \text { D }\end{array}$ GTTTGTCAATAACTGAAAACTTAGCACAGATTGGTGTTAAAATACCATCATCAATAACAG $\begin{array}{llllll}\mathbf{8 5 0} & \mathbf{8 6 0} & \mathbf{8 7 0} & \mathbf{8 8 0} & \mathbf{8 9 0} & \mathbf{9 0 0}\end{array}$

$\begin{array}{llllllllllllllllllll}R & L & Q & T & I & B & N & E & K & E & Q & S & K & N & N & A & D & K & A & A\end{array}$ ATCGATTACAAACAATTGAGAACGAAAAAGAACAGAGTAAGAATAACGCAGACAAAGCTG $\begin{array}{llllll}910 & 920 & 930 & 940 & 950 & 960\end{array}$

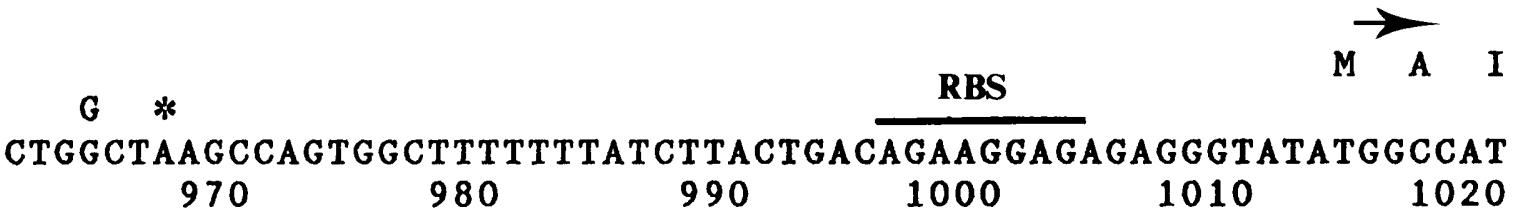

ORF 3 (autolysin)

$\begin{array}{llllllllllllllllllll}K & \mathbf{V} & \mathbf{V} & \mathbf{K} & \mathbf{N} & \mathbf{L} & \mathbf{V} & \mathbf{S} & \mathbf{K} & \mathbf{S} & \mathbf{K} & \mathbf{Y} & \mathbf{G} & \mathbf{L} & \mathbf{K} & \mathbf{C} & \mathbf{P} & \mathbf{N} & \mathbf{P} & \mathbf{M}\end{array}$ TAAAGTTGTAAAGAATCTAGTCTCTAAATCAAAGTATGGATTGAAATGTCCTAATCCAAT $\begin{array}{llllll}1030 & 1040 & 1050 & 1060 & 1070 & 1080\end{array}$

$\begin{array}{llllllllllllllllllll}\mathbf{K} & \mathbf{A} & \mathbf{E} & \mathbf{Y} & \mathbf{I} & \mathbf{T} & \mathbf{I} & \mathbf{H} & \mathbf{N} & \mathbf{T} & \mathbf{A} & \mathbf{N} & \mathbf{D} & \mathbf{A} & \mathbf{S} & \mathbf{A} & \mathbf{A} & \mathbf{N} & \mathbf{E} & \mathbf{I}\end{array}$ GAAAGCTGAATATATCACTATTCATAACACTGCGAATGATGCTTCAGCAGCCAATGAGAT $\begin{array}{llllll}1090 & 1100 & 1110 & 1120 & 1130 & 1140\end{array}$

$\begin{array}{llllllllllllllllllll}\mathbf{S} & \mathbf{Y} & \mathbf{M} & \mathbf{K} & \mathbf{N} & \mathbf{N} & \mathbf{S} & \mathbf{S} & \mathbf{S} & \mathbf{T} & \mathbf{S} & \mathbf{P} & \mathbf{H} & \mathbf{F} & \mathbf{A} & \mathbf{V} & \mathbf{D} & \mathbf{D} & \mathbf{K} & \mathbf{Q}\end{array}$ TTCTTACATGAAGAATAACTCTAGCTCAACAAGTTTTCACTTTGCAGTAGACGATAAACA $\begin{array}{llllll}1150 & 1160 & 1170 & 1180 & 1190 & 1200\end{array}$

$\begin{array}{llllllllllllllllllll}\mathbf{V} & \mathbf{I} & \mathbf{Q} & \mathbf{G} & \mathbf{I} & \mathbf{P} & \mathbf{T} & \mathbf{N} & \mathbf{R} & \mathbf{N} & \mathbf{A} & \mathbf{W} & \mathbf{H} & \mathbf{T} & \mathbf{G} & \mathbf{D} & \mathbf{G} & \mathbf{T} & \mathbf{N} & \mathbf{G}\end{array}$ AGTCATTCAAGGTATTCCAACGAATCGTAACGCTTGGCACACAGGAGATGGAACAAACGG 1210 1220

1230

1240

1250

1260 
$\begin{array}{llllllllllllllllllll}T & G & N & R & K & S & I & G & V & E & I & C & Y & S & K & S & G & G & V & R\end{array}$ TACAGGGAATCGCAAGTCTATTGGTGTCGAAATTTGTTATAGCAAG'CAGGAGGGGTACG 1270 1280 1290 1300

1310 1320

$\begin{array}{llllllllllllllllllll}\mathbf{Y} & \mathrm{K} & \mathbf{A} & \mathbf{A} & \mathrm{B} & \mathrm{K} & \mathbf{L} & \mathbf{A} & \mathbf{I} & \mathbf{K} & \mathbf{F} & \mathbf{V} & \mathbf{A} & \mathbf{Q} & \mathbf{L} & \mathbf{L} & \mathbf{K} & \mathbf{E} & \mathbf{R} & \mathbf{G}\end{array}$ ATATAAGGCAGCGGAAAAGCTTGCTATTAAGTTTGTGGCTCAGCTACTTAAAGAACGTGG 1330

1340

1350

1360

1370

1380

$\begin{array}{llllllllllllllllllll}\mathbf{W} & \mathbf{G} & \mathbf{I} & \mathbf{D} & \mathbf{R} & \mathbf{V} & \mathbf{R} & \mathbf{K} & \mathbf{H} & \mathbf{Q} & \mathbf{D} & \mathbf{W} & \mathbf{N} & \mathbf{G} & \mathbf{K} & \mathbf{Y} & \mathbf{C} & \mathbf{P} & \mathbf{H} & \mathbf{R}\end{array}$ ATGGGGTATTGATCGAGTCCGCAAACATCAAGACTGGAATGGTAAGTATTGCCCGCACCG $\begin{array}{llllll}1390 & 1400 & 1410 & 1420 & 1430 & 1440\end{array}$

$\begin{array}{llllllllllllllllllll}I & \mathbf{L} & \mathbf{S} & \mathbf{B} & \mathbf{G} & \mathrm{R} & \mathbf{W} & \mathrm{I} & \mathbf{Q} & \mathbf{V} & \mathbf{K} & \mathbf{T} & \mathbf{A} & \mathbf{I} & \mathbf{B} & \mathbf{A} & \mathbf{B} & \mathbf{L} & \mathbf{K} & \mathbf{K}\end{array}$ CATTTTGTCAGAGGGAAGATGGATTCAAGTTAAGACTGCAATTGAAGCAGAATTGAAAAA $\begin{array}{rrrrrr}1450 & 1460 & 1470 & 1480 & 1490 & 1500\end{array}$

$\begin{array}{llllllllllllllllllll}L & \mathbf{G} & \mathbf{G} & \mathbf{K} & \mathbf{T} & \mathbf{N} & \mathbf{S} & \mathbf{S} & \mathbf{K} & \mathbf{A} & \mathbf{S} & \mathbf{V} & \mathbf{A} & \mathbf{K} & \mathbf{K} & \mathbf{K} & \mathbf{T} & \mathbf{T} & \mathbf{N} & \mathbf{T}\end{array}$ GTTGGGCGGAAAAACAAACTCAAGCAAAGCAAGTGTAGCTAAAAAGAAAACAACAAACAC 1520 1530 1540

1550 1560

$\begin{array}{llllllllllllllllllll}\mathbf{S} & \mathbf{S} & \mathbf{K} & \mathbf{K} & \mathbf{T} & \mathbf{S} & \mathbf{Y} & \mathbf{A} & \mathrm{L} & \mathbf{P} & \mathbf{S} & \mathbf{G} & \mathbf{I} & \mathbf{P} & \mathbf{K} & \mathbf{V} & \mathbf{K} & \mathbf{S} & \mathbf{P} & \mathbf{M}\end{array}$ AAGCAGCAAAAAAACGTCATATGCGCTACCATCCGGTATTTTTAAAGTGAAGAGCCCAAT 1570 1580 1590 1600

1610 1620

$\begin{array}{llllllllllllllllllll}M & R & G & \mathbf{B} & \mathrm{K} & \mathrm{V} & \mathbf{T} & \mathbf{Q} & \mathrm{I} & \mathbf{Q} & \mathrm{K} & \mathbf{A} & \mathbf{L} & \mathbf{A} & \mathbf{A} & \mathbf{L} & \mathbf{Y} & \mathbf{P} & \mathbf{Y} & \mathbf{P}\end{array}$ GATGAGAGGGGAAAAGGTAACACAAATTCAAAAAGCACTGGCTGCACTATACTTTTACCC 1630

1640

1650

1660

1670

1680

$\begin{array}{llllllllllllllllllll}D & K & G & A & K & N & N & G & I & D & G & V & Y & G & P & K & T & A & D & A\end{array}$ GGATAAAGGAGCAAAAAACAACGGCATTGACGGCGTGTATGGTCCGAAAACAGCAGATGC $\begin{array}{llllll}1690 & 1700 & 1710 & 1720 & 1730 & 1740\end{array}$

$\begin{array}{llllllllllllllllllll}I & R & R & P & Q & \text { S } & \text { M } & \text { Y } & \text { G } & \text { L } & \text { T } & \text { Q } & \text { D } & \text { G } & \text { I } & \text { Y } & \text { G } & \text { P } & K & \text { T }\end{array}$ AATTAGACGATTCCAGTCTATGTACGGGCTTACTCAAGACGGTATTTACGGACCAAAAAC 1750

1760

1770

1780

1790

1800

$\begin{array}{llllllllll}\text { K } & \text { A } & \text { K } & \text { L } & \text { B } & \text { A } & \text { L } & \text { L } & \text { K } & *\end{array}$ GAAAGCGAAACTTGAAGCTCTCTTGAAGTAAATAAATAGTCTCCTTGAGTATCTTTCTCA 1810 1820 1830

1840

1850 1860

AGGAGATACTTATGTTTATTTTGTTACAGATAGTTCAAAATTATTCTAATATTTGAGTAA 1870 1880 1890 1900

1910

1920 
AAAGTATTATTTTTCTAGTCTGAACATAATGTTATCATTTACATGTAAATAATTTAAAAG 1930

1940

1950

1960

1970

1980

\section{$\rightarrow$ ORF 4}

$\begin{array}{lllllllllllllll}M & \mathbf{F} & \mathbf{K} & \mathbf{K} & \mathbf{L} & \mathbf{L} & \mathbf{L} & \mathbf{A} & \mathbf{T} & \mathbf{S} & \mathbf{A} & \mathbf{L} & \mathbf{T} & \mathbf{F} & \mathbf{S}\end{array}$ AAAGGGATTGATTTCATGTTTAAGAAATTACTTTTAGCAACATCTGCATTAACATTCTCT 1990 2000 2010 2020 2030

2040

$\begin{array}{llllllllllllllllllll}\text { L } & \text { S } & \text { L } & \text { V } & \text { L } & \text { P } & \text { L } & \text { D } & \text { G } & \text { H } & \text { A } & \text { K } & \text { A } & \text { Q } & \text { E } & \text { V } & \text { T } & \text { L } & \mathbf{Q} & A\end{array}$ TTATCATTAGTTCTTCCGTTGGATGGACATGCCAAAGCTCAAGAGGTAACATTACAGGCA 2050 2060 2070 2080 2090

2100

$\begin{array}{llllllllllllllllllll}\mathbf{Q} & \mathbf{Q} & \mathbf{E} & \mathbf{V} & \mathbf{T} & \mathbf{Y} & \mathbf{Q} & \mathbf{T} & \mathbf{P} & \mathbf{V} & \mathbf{K} & \mathbf{L} & \mathbf{S} & \mathbf{B} & \mathbf{L} & \mathbf{P} & \mathbf{T} & \mathbf{N} & \mathbf{T} & \mathbf{T}\end{array}$ CAGCAGGAAGTCACTTATCAAACTCCCGTTAAACTATCCGAATTACCAACTAATACAACT 2110 2120

2130 2140

2150

2160

$\begin{array}{llllllllllllllllllll}\mathbf{E} & \mathbf{Q} & \mathbf{S} & \mathbf{G} & \mathbf{B} & \mathbf{P} & \mathbf{H} & \mathbf{T} & \mathbf{N} & \mathbf{G} & \mathbf{I} & \mathbf{K} & \mathbf{K} & \mathbf{W} & \mathbf{I} & \mathbf{A} & \mathbf{K} & \mathbf{E} & \mathbf{A} & \mathbf{M}\end{array}$ GAACAATCTGGTGAATTTCACACAAATGGTATTAAAAAATGGATTGCTAAAGAAGCAATG 2170 2180 2190 2200 2210

2220

$\begin{array}{llllllllllllllllllll}K & A & T & A & S & A & \text { L } & \text { R } & \text { H } & \text { G } & \text { G } & \text { R } & \text { I } & \text { V } & G & \text { G } & \text { V } & \text { V } & \text { D } & \text { B }\end{array}$ AAGGCAACAGCCAGTGCGCTTCGACATGGTGGGAGAATTGTTGGTGAGGTAGTCGATGAG 2230 2240 2250 2260

2270

2280

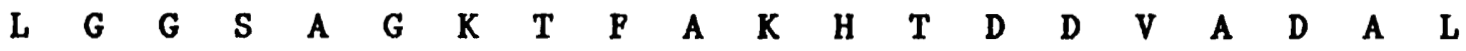
TTAGGTGGATCAGCAGGAAAAACATTCGCAAAACATACTGATGATGTAGCAGATGCTTTG 2290 2300

2310

2320

2330

2340

$\begin{array}{llllllllllllllllllll}\mathbf{D} & \mathbf{B} & \mathbf{L} & \mathbf{V} & \mathrm{K} & \mathbf{R} & \mathrm{G} & \mathbf{D} & \mathbf{V} & \mathbf{V} & \mathbf{E} & \mathbf{D} & \mathbf{A} & \mathrm{I} & \mathrm{I} & \mathbf{D} & \mathrm{T} & \mathbf{V} & \mathbf{S} & \mathbf{S}\end{array}$ GACGAGTTAGTTAAACGAGGTGACGTTGTGGAGGACGCAATTATTGACACGGTTTCCTCA 2350 2360 2370 2380 2390

2400

$\begin{array}{llllllllllllllllllll}\mathbf{Y} & \mathbf{L} & \mathbf{I} & \mathbf{D} & \mathbf{A} & \mathbf{G} & \mathbf{V} & \mathbf{K} & \mathbf{S} & \mathbf{S} & \mathbf{T} & \mathbf{A} & \mathbf{R} & \mathbf{T} & \mathbf{I} & \mathbf{A} & \mathbf{S} & \mathbf{V} & \mathbf{P} & \mathbf{T}\end{array}$ TATCTAATTGATGCTGGTGTAAAATCTTCTACAGCTAGAACTATTGCAAGTGTATTTACT 2410 2420 2430 2440 2450

2460

$\begin{array}{lllll}\mathbf{P} & \mathbf{L} & \mathbf{A} & \mathbf{P} & *\end{array}$

$\rightarrow$ ORF 5

TTCTTAGCTTTTTAATTGAGGTGATTTGAATTGGTAACAGTAGAAGAAAGGCTTGACAAC 2470

2480

2490

2500

2510

2520

$\begin{array}{llllllllllllllllllll}\text { L } & B & K & K & \text { V } & \text { E } & \text { K } & \mathbf{Q} & \text { A } & \text { P } & \mathbf{Q} & \text { L } & \text { R } & \text { L } & \text { V } & \mathbf{Q} & \mathbf{Q} & \text { L } & A & A\end{array}$ CTAGAAAAAAAATCGAGAAGCAGGCTTTTCAACTAAGGTTAGTCCAACAATTAGCAGCT 2530 2540 2550

2560

2570

2580 


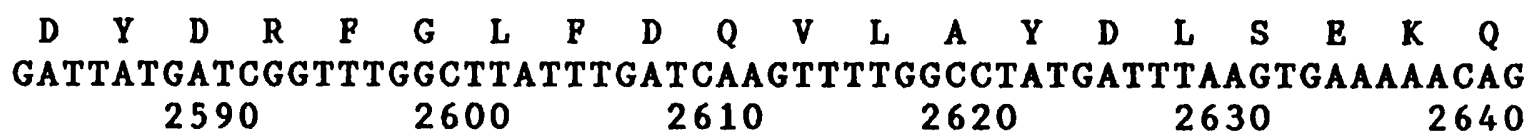

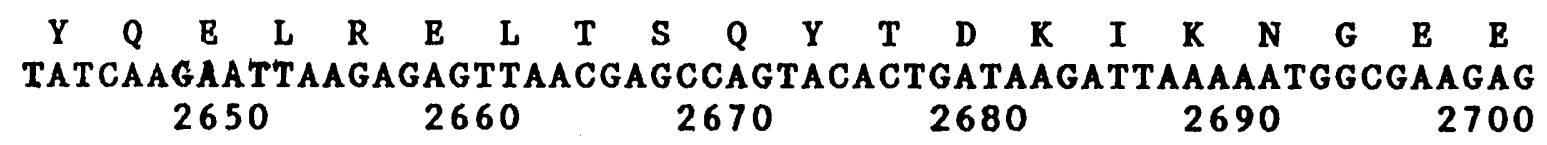

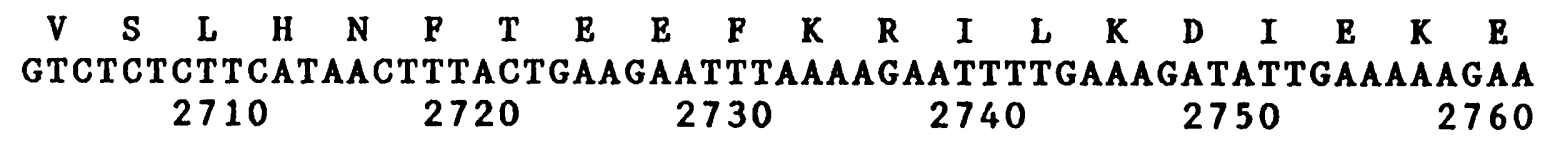

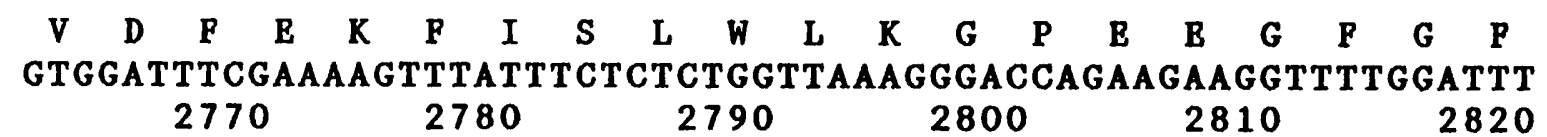

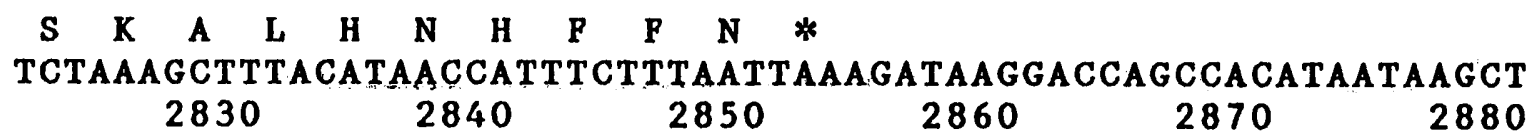

GGTCTTTCTTTATTTTCCCTCAAGTTCGAACTCCTATGAACAGAATACCAGGTATCTATC $\begin{array}{llllll}2890 & 2900 & 2910 & 2920 & 2930 & 2940\end{array}$

CTTCCAAATATATTGTTATTAGCTTGAGGTTTGTGTGTTTTTCTTCATTAATCATAGAA $\begin{array}{llllll}2950 & 2960 & 2970 & 2980 & 2990 & 3000\end{array}$

TTC

Analysis of autolysin activity by renaturing SDS-PAGE

Soluble extracts of $E$. coli DH5 $\alpha$ containing pUBS1 or pSFP102 were prepared and subjected to SDS-PAGE. After renaturation, no lytic activity was associated with the $E$. coli DH5 $\alpha$ (pUBS1) extract (Fig. 3, track 4), while proteins from $E$. coli DH5 $\alpha$ (pSFP102) showed two bands of lytic activity at 30 and $21 \mathrm{kDa}$ (Fig. 3, track 5). An exponentially growing culture $\left(\mathrm{OD}_{600}=0.5\right)$ of $E$. coli $\mathrm{DH} 5 \alpha(\mathrm{pSFP} 102)$ was harvested and resuspended in SDS-PAGE sample buffer, then boiled for $3 \mathrm{~min}$. The soluble extract was separated by SDS-PAGE. After renaturation, only the $30 \mathrm{kDa}$ band was present (results not shown). However, if this extract was incubated at $37^{\circ} \mathrm{C}$ for $2 \mathrm{~h}$, the $21 \mathrm{kDa}$ band became the predominant form, with a concomitant decrease in the level of the
$30 \mathrm{kDa}$ band. Corresponding cloned gene products could be visualized by Coomassie Blue staining against the background of E. coli DH5 $\alpha$ proteins (Fig. 3, tracks 2 and 3).

Mode of action of the cloned autolysin

The bond specificity of the cloned lytic enzyme can be ascertained by the detection of newly exposed groups on the peptidoglycan after hydrolysis. If the enzyme is a muramidase or glucosaminidase new reducing groups should be detected; if an amidase or endopeptidase new amino termini will be detected. Fig. 4 shows the kinetics of hydrolysis of a suspension of purified B. subtilis 168 
(a)

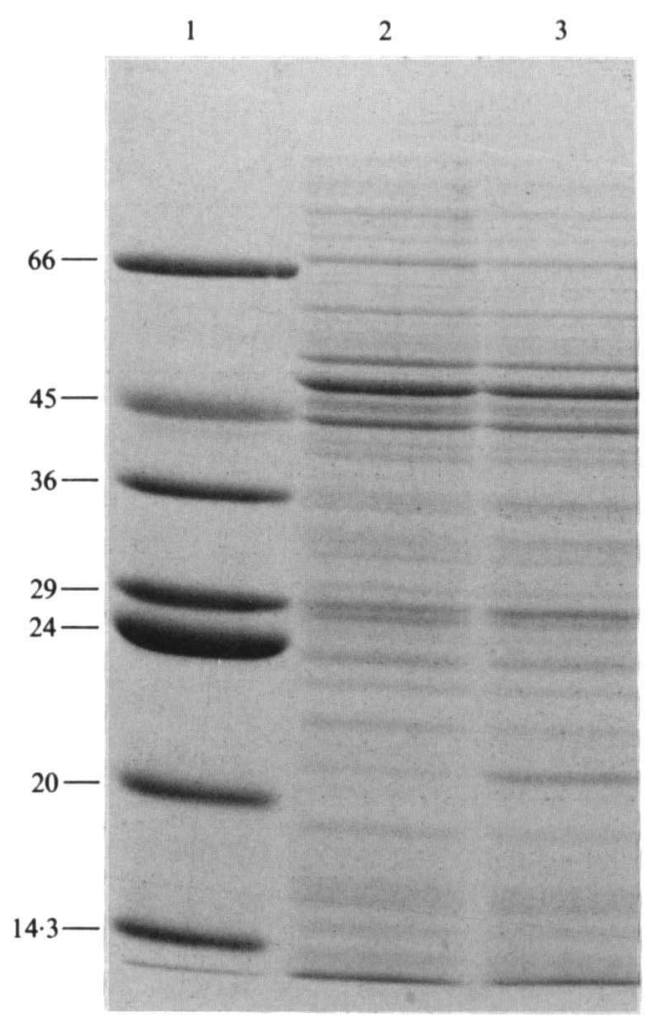

(b)

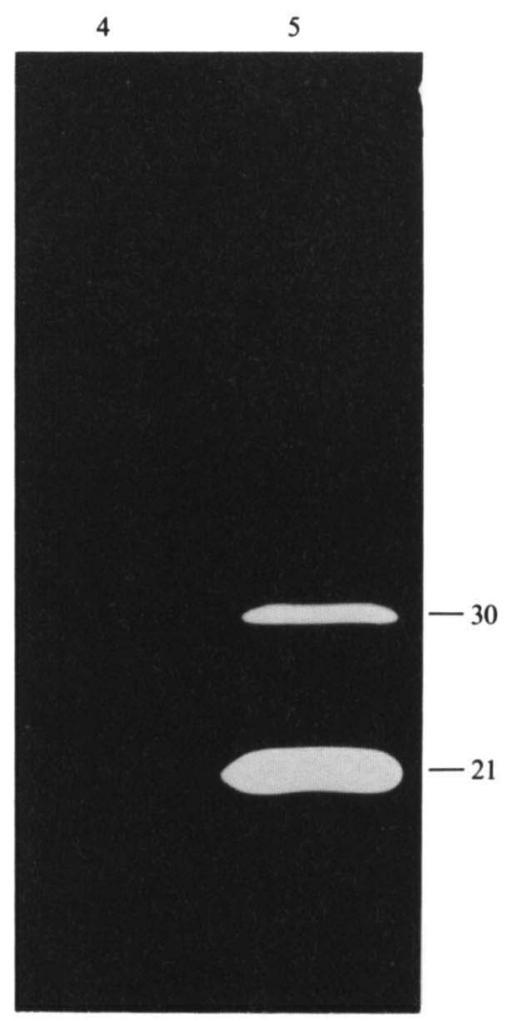

Fig. 3. Analysis of autolysin activity by renaturing SDS-PAGE. Samples were prepared as described in Methods, and separated by $11 \%$ (w/v) SDS-PAGE. (a) Coomassie-Blue-stained gel; $(b)$ renaturing gel containing $0 \cdot 1 \%$ purified $B$. subtilis 168 vegetative cell walls treated as described in Methods. Tracks: 1, molecular mass markers (Dalton MK VII-L) of sizes shown (kDa); 2 and 4, E. coli DH5 $\alpha$ (pUBS1) extract $(1 \mu \mathrm{l}) ; 3$ and $5, E$. coli $\mathrm{DH} 5 \alpha(\mathrm{kDa})$ (pSFP102) extract $(1 \mu \mathrm{l})$. The molecular masses of the zones of lytic activity are marked.

vegetative cell walls $\left(5 \mathrm{mg} \mathrm{ml}^{-1}\right)$ by the enzyme-containing extract from $E$. coli DH5 $\alpha(\mathrm{pSFP} 102)$. After $30 \mathrm{~min}$ treatment with the enzyme, the $\mathrm{OD}_{450}$ of the wall suspension had been reduced by $>90 \%$. An equivalent amount of extract from $E$. coli DH5 $\alpha$ (pUBS1) had no effect on the wall suspension as measured by loss in $\mathrm{OD}_{450}$ over $45 \mathrm{~min}$. Concomitant with the decrease in $\mathrm{OD}_{450}$ was a marked increase in the number of free amino termini (Fig. 4, A); after $30 \mathrm{~min}$ digestion, $637 \mathrm{nmol}$ (mg walls) ${ }^{-1}$ were released. In contrast over this time period only $10 \mathrm{nmol}(\mathrm{mg} \text { walls })^{-1}$ of new reducing groups appeared. To test whether this increase in amino termini was due to an amidase or an endopeptidase, the FDNB-labelled samples [ 45 min digestion with $E$. coli DH5 $\alpha$ (pSFP102) extract] were acid-hydrolysed and separated by TLC on silica gel plates, which allows identification of the labelled amino acids by comparison with FDNB-labelled amino acid standards (Ghuysen $e t$ $a l ., 1966)$. The only major spot to appear on the TLC after hydrolysis of the walls by the cloned autolysin

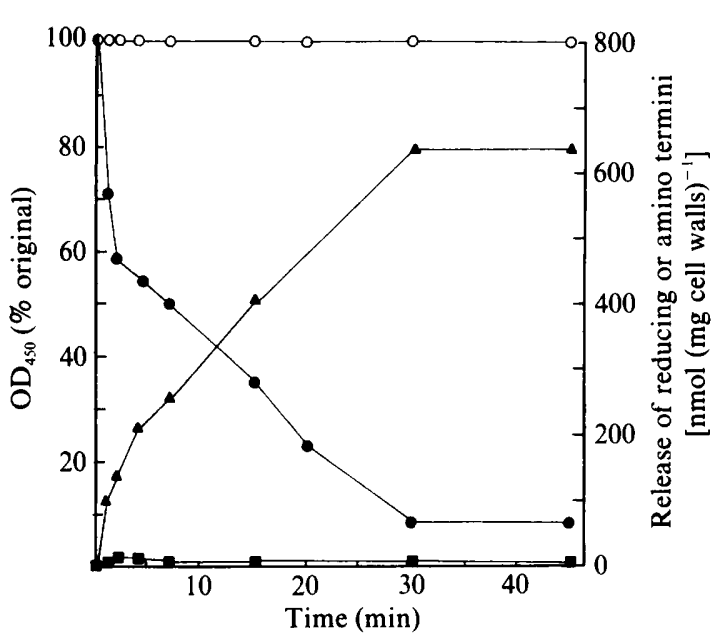

Fig. 4. Digestion of $B$. subtilis 168 purified vegetative cell walls by autolysin-containing extract. Walls were digested as described in Methods at $5 \mathrm{mg} \mathrm{ml}^{-1}$ with extracts from $E$. coli DH $5 \alpha$ containing plasmid pUBS1 (open symbols) or pSFP102 (closed symbols). Samples were removed at various intervals for the determination of $\mathrm{OD}_{450}$ $(\mathrm{O}, \bullet)$, of released reducing groups $(\boldsymbol{C})$ and free amino groups $(\boldsymbol{\Delta})$. 


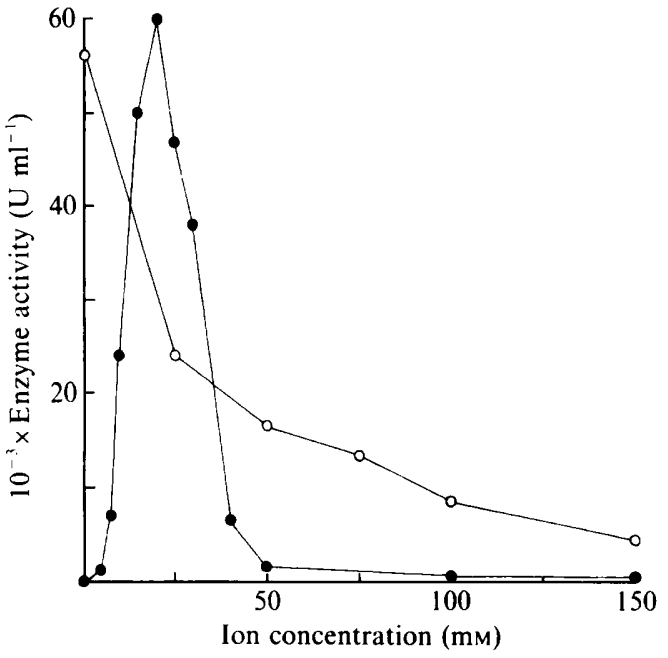

Fig. 5. Effect of ion concentration on enzyme activity. Enzyme activity was measured as described in Methods, using purified B. subtilis 168 vegetative cell walls as substrate, and the equivalent of $1 \mu \mathrm{l}$ of enzyme extract per $1 \mathrm{ml}$ of reaction mixture. concentration on enzyme activity; $\mathrm{O}$, effect of $\mathrm{LiCl}$ concentration on enzyme activity.

corresponded to that of the FDNB-labelled amino acid derivative $N$-2,3-dinitrophenyl-DL-alanine (DNP-alanine) (results not shown). However, this does not differentiate between the possibility of the enzyme being an $\mathrm{N}$-acetylmuramyl-L-alanine amidase (amidase) or a meso-diaminopimelate-D-alanine endopeptidase, both of which would cause an increase in alanine $\mathrm{N}$-termini. To test which of these possibilities was correct, $\mathrm{L}-\left[{ }^{14} \mathrm{C}\right] \mathrm{ala}-$ nine-labelled walls were prepared. Digestion using the enzyme extract, FDNB-labelling, acid hydrolysis and TLC separation were as above. After counting, $80 \%$ of the radioactivity in the FDNB-labelled acid hydrolysate was found to correspond to DNP-alanine, underivatized alanine remaining at the origin. This constitutes a 14-fold increase in the number of free $\mathrm{L}$-alanine $\mathrm{N}$-termini on treatment with the enzyme as compared to FDNB-labelled acid-hydrolysed undigested walls. No soluble FDNB-labelled material was released over 45 min by walls treated with the $E$. coli DH5 (pUBS1) extract. Thus, the new $\mathrm{N}$-termini are likely to be L-alanine termini, and the enzyme is probably an amidase.

\section{Effect of ion concentration on autolysin activity}

The activity of the cloned autolysin was found to be highly dependent on divalent cation concentration. Activity was completely inhibited at $\mathrm{MgCl}_{2}$ concentrations $<1 \mathrm{mM}$ (Fig. 5) or by the addition of $1 \mathrm{mM}$ EDTA. A sharp peak of $\mathrm{MgCl}_{2}$ activation was found,
Table 1. Substrate specificity of the cloned B. subtilis 168 autolysin

The activity of the enzyme on various substrates (see Methods) was measured as a percentage of the control activity on B. subtilis 168 vegetative cell walls $(100 \%, 46 \mathrm{U})$. An equivalent amount of $E$. coli DH $5 \alpha(\mathrm{pUBS} 1)$ enzyme preparation contained $<0.1 \%$ of enzyme activity compared to the above control.

\begin{tabular}{lr}
\hline \hline \multicolumn{1}{c}{ Substrate } & $\begin{array}{c}\text { Activity } \\
(\%)\end{array}$ \\
\hline B. subtilis 168 vegetative cell walls & 100 \\
B. subtilis 168 vegetative cell walls (teichoic acid removed) & 48 \\
B. sphaericus 9602 vegetative cell walls & 61 \\
B. megaterium KM vegetative cell walls & 70 \\
$M$. luteus 4698 cell walls & 65 \\
L. arabinosus 6376 cell walls & 46 \\
E. coli ER 1458 cell walls & 0 \\
$B$. megaterium KM spore cortex & 295 \\
$B$. subtilis 168 vegetative cells & 17 \\
$B$. megaterium KM vegetative cells & 122 \\
$M$. luteus 4698 cells & 2 \\
\hline \hline
\end{tabular}

with maximal activity at $20 \mathrm{mM}$. At $50 \mathrm{mM}-\mathrm{MgCl}_{2}$, the enzyme retained $<5 \%$ of its maximal activity. $\mathrm{Mg}^{2+}$ ions could be replaced by other divalent cations. $\mathrm{MnCl}_{2}$ or $\mathrm{CaCl}_{2}$ at $20 \mathrm{mM}$ gave $45 \%$ and $54 \%$ of the activity, respectively, as compared with an equivalent $\mathrm{MgCl}_{2}$ concentration (results not shown). The enzyme was inhibited by even relatively low concentrations of $\mathrm{LiCl}$; $150 \mathrm{mM}-\mathrm{LiCl}$ inhibited enzyme activity by $>90 \%$ (Fig. 5).

\section{Substrate specificity of the cloned autolysin}

The enzyme extract was tested for its ability to hydrolyse a wide range of peptidoglycan substrates (Table 1). Purified cell walls from all Gram-positive bacteria tested were hydrolysed effectively. On B. megaterium $\mathrm{KM}$ spore cortex, the best substrate, the enzyme had three times more activity than on the control $B$. subtilis 168 vegetative cell walls. Intact Bacillus vegetative cells were also hydrolysed, although to a lesser extent than purified walls. Acid treatment to remove teichoic acids (Hughes et al., 1968) led to a $52 \%$ decrease in activity.

\section{Binding of the autolysin to purified cell walls}

The autolysin bound well to vegetative cell walls of various species and to $B$. megaterium $\mathrm{KM}$ spore cortex (Table 2). However, this adsorption was totally $\mathbf{M g}^{2+}$ dependent; no enzyme at all became bound to $B$. subtilis 168 vegetative cell walls in the absence of $\mathrm{Mg}^{2+}$. 
Table 2. Binding of the B. subtilis 168 autolysin to purified cell walls

Enzyme extract $(2 \mu \mathrm{l}, 100 \mathrm{U})$ was incubated in $1 \mathrm{ml} 25 \mathrm{~mm}$ Tris/ $\mathrm{HCl}$ (pH 7.5) with $20 \mathrm{~mm}-\mathrm{MgCl}_{2}$ (unless otherwise stated) containing $1 \mathrm{mg}$ purified cell walls at $0{ }^{\circ} \mathrm{C}$ for $15 \mathrm{~min}$. The walls were removed by centrifugation $\left(14000 \mathrm{~g}, 5 \mathrm{~min}, 4^{\circ} \mathrm{C}\right)$ and the supernatant was assayed for remaining enzyme activity in the standard assay. The reduction in $\mathrm{OD}_{450}$ of the walls containing adsorbed enzyme was also measured in reaction buffer at $37^{\circ} \mathrm{C}$.

\begin{tabular}{lccc}
\hline \hline \multicolumn{1}{c}{ Source of wall } & $\begin{array}{c}\text { Adsorbed } \\
\text { activity } \\
(\mathrm{U})\end{array}$ & $\begin{array}{c}\text { Soluble } \\
\text { activity } \\
(\mathrm{U})\end{array}$ & $\begin{array}{c}\text { Percentage } \\
\text { adsorbed } \\
(\%)\end{array}$ \\
\hline B. subtilis 168 vegetative cells & 55 & 22 & 71 \\
$\begin{array}{l}\text { B. subtilis } 168 \text { vegetative cells } \\
\text { (no } \mathrm{Mg}^{2+} \text { ) }\end{array}$ & 0 & 110 & 0 \\
B. sphaericus 9602 vegetative cells & 80 & 11 & 88 \\
M. luteus 4698 cells & 72 & 30 & 71 \\
B. megaterium KM spores & 70 & 14 & 83 \\
\hline \hline
\end{tabular}

\section{Discussion}

This work describes the cloning and analysis of a lowmolecular-mass autolysin of $B$. subtilis 168 . During the preparation of this manuscript Kuroda \& Sekiguchi (1990) published the cloning and sequencing of this enzyme and designated the gene $c w l A$. They sequenced a $1.1 \mathrm{~kb}$ region containing the autolysin gene, the DNA sequence of which exactly matches that presented here and their initial mapping data gives the same approximate position on the $B$. subtilis 168 chromosome. In reference to the above work, I have retained the same nomenclature of $c w 1 A$ for the autolysin gene. Sequencing of the $c w 1 A$-containing region $(3 \mathrm{~kb})$ reveals five ORFs, the central one of which encodes the autolysin. The expression of the autolysin gene in pSFP100 is not IPTGinducible and thus the gene may be transcribed from its own promoter, even in $E$. coli. The transcriptional regulation of $c w I A$ is at present unclear, although it is possibly controlled by the vegetative sigma factor, $\sigma^{\mathrm{A}}$. Expression of autolysin genes has also been linked to the minor sigma factor, $\sigma^{\mathrm{D}}$ (Marquez et al., 1990). Promoter mapping and expression analysis in mutant backgrounds will resolve these problems. Whether $c w 1 A$ forms part of an operon or is transcribed singly is also uncertain.

The autolysin characterized in this work is an amidase which cleaves the peptide side chain from the glycan backbone of the peptidoglycan. In E. coli $\mathrm{DH} 5 \alpha$, the enzyme is processed from a 30 to a $21 \mathrm{kDa}$ form, although both forms show autolytic activity. A putative signal cleavage site is present after $\mathrm{Ala}_{39}$ (base 1129, Fig. 2) as described by Kuroda \& Sekiguchi (1990). Proteolytic processing of autolysins from higher-molecularmass precursors has been reported in both $B$. megaterium
KM and Streptococcus faecium (Foster \& Johnstone, 1988; Kawamura \& Shockman, 1983), although whether this processing occurs in vivo in $B$. subtilis 168 is unknown. Both the major $50 \mathrm{kDa}$ (Herbold \& Glaser, 1975; Rogers et al., 1984) and the $30 / 21 \mathrm{kDa}$ (this study) amidase require $\mathrm{Mg}^{2+}$ for activity and have optima at $20 \mathrm{~mm}$. However, the $\mathrm{LiCl}$ sensitivity of the enzymes differs; the 30/21 and $50 \mathrm{kDa}$ amidases are inhibited by $92 \%$ and $30 \%$ by $150 \mathrm{~mm}-\mathrm{LiCl}$, respectively (Fig. 5; Herbold \& Glaser, 1975).

The $30 / 21 \mathrm{kDa}$ amidase is able to hydrolyse the isolated peptidoglycan of all Gram-positive bacteria tested, including $B$. sphaericus 9602 , which is resistant to digestion by lysozyme, mutanolysin and Charalopsis muramidase (P. J. White, personal communication). The greater activity using $B$. megaterium $\mathrm{KM}$ spore cortex as substrate may be due to the low incidence of crosslinkage in the spore cortex as compared to vegetative cell peptidoglycan (Tipper \& Gauthier, 1972) and thus fewer bonds need to be hydrolysed for solubilization to occur. The enzyme also binds strongly to its peptidoglycan substrate (Table 2). However, this binding is $\mathbf{M g}^{2+}$ sensitive and so the dependence of activity on $\mathrm{Mg}^{2+}$ may be a result of the inability of the enzyme to bind to its substrate.

The physiological function of the $30 / 21 \mathrm{kDa}$ amidase is at present unknown. The insertionally inactivated mutant was able to grow and divide ostensibly as wildtype. The roles of the major $50 \mathrm{kDa}$ amidase and $90 \mathrm{kDa}$ glucosaminidase are also obscure. The only autolysin to be studied in detail at the molecular level is the major amidase of Streptococcus pneumoniae (Garcia et al., 1986). When the gene for this enzyme was insertionally inactivated the only altered properties were an inability to lyse at the end of exponential growth and an increased resistance to penicillin-induced lysis (Tomasz et al., 1988). Thus there may be some redundancy in autolysin function, the enzymes acting in concert, with one autolysin being able to compensate for the loss of another. The total complement of $B$. subtilis 168 autolysins is unknown. As well as the two major vegetative autolysins, two sporulation-specific enzymes have also been identified (Guinand et al., 1976). In $B$. megaterium $\mathrm{KM}$, a germination-specific lytic enzyme has also been purified and characterized (Foster \& Johnstone, 1987, 1988). Using renaturing SDS-PAGE, $B$. subtilis ATCC 6633 has been shown to have at least seven possible vegetative autolysins (Leclerc \& Asselin, 1989), although the actual number of autolysin genes involved is unknown. An in-depth profile of the mutant inactivated in the 30/21 kDa amidase may reveal a subtle phenotype, however, autolysin function may remain obscure until multiple autolysin-deficient strains are produced, as only then will their joint role become apparent. 
I am very grateful to Dr Anne Moir for her help during this work and for her critical reading of the manuscript and to Professor Dimitri Karamata for helpful advice and discussion. This work was carried out during the tenure of the J. G. Graves Medical Research Fellowship. I also acknowledge the SERC for use of the VAX computing facilities at Daresbury.

\section{References}

ANagnostopoulos, C. \& Spizizen, J. (1961). Requirements for transformation in Bacillus subtilis. Journal of Bacteriology 81, $741-746$

Biavasco, F., Pruzzo, C. \& Thomas, C. (1988). Cloning and expression of the Staphylococcus aureus glucosaminidase in Escherichia coli. FEMS Microbiology Letters 49, 137-142.

Dedonder, R. A., Lepasant, J.-A., Lepasant-KejZlarova, J., Billault, A., Steinmetz, M. \& Kunst, F. (1977). Construction of a kit of reference strains for rapid genetic mapping in Bacillus subtilis 168. Applied and Environmental Microbiology 33, 989-993.

Dubnau, D., Goldthwaite, C., Smith, I. \& Marmur, J. (1967). Genetic mapping in Bacillus subtilis. Journal of Molecular Biology 27, 163-185.

ForSBERG, C. \& Rogers, H. J. (1971). Autolytic enzymes in growth of bacteria. Nature, London 229, 272-273.

Foster, S. J. \& JoHNSTONE, K. (1987). Purification and properties of a germination-specific cortex-lytic enzyme from spores of Bacillus megaterium KM. Biochemical Journal 242, 573-579.

FosTER, S. J. \& JoHNSTONE, K. (1988). Germination-specific cortexlytic enzyme is activated during triggering of Bacillus megaterium KM spore germination. Molecular Microbiology 2, 727-733.

Garcia, P., Garcia, J. L., Garcia, E. \& Lopez, R. (1986). Nucleotide sequence and expression of the pneumococcal autolysin gene from its own promoter in Escherichia coli. Gene 43, 265-272.

GHuYsen, J.-M., Tipper, D. J. \& Strominger, J. L. (1966). Enzymes that degrade bacterial cell walls. Methods in Enzymology 8, 685-699.

Guinand, M., Michel, G. \& Balassa, G. (1976). Lytic enzymes in sporulating Bacillus subtilis. Biochemical and Biophysical Research Communications 68, 1287-1293.

HanaHAN, D. (1983). Studies on transformation of Escherichia coli with plasmids. Journal of Molecular Biology 166, 557-580.

HENIKOFF, S. (1984). Unidirectional digestion with exonuclease III creates targeted breakpoints for DNA sequencing. Gene 28, 351-359.

HERBOLD, D. R. \& GLASER, L. (1975). Bacillus subtilis $N$-acetylmuramic acid L-alanine amidase. Journal of Biological Chemistry 250, 1676-1682.

Hughes, R. C., Pavlik, J. G., Rogers, H. J. \& Tanner, P. J. (1968). Organization of polymers in the cell walls of some Bacilli. Nature, London 219, 642-644.

HUYNH, T. V., Young, R. A. \& DAvIs, R. W. (1985). Constructing and screening cDNA libraries in $\lambda$ gt 10 and $\lambda g t 11$. In DNA Cloning, vol. 1, pp. 49-78. Edited by D. M. Glover. Oxford: IRL Press.

JaYASWAL, R. K., LeE, Y.-I. \& Wilkinson, B. J. (1990). Cloning and expression of a Staphylococcus aureus gene encoding a peptidoglycan hydrolase activity. Journal of Bacteriology 172, 5783-5788.

JOHNSTONE, K. \& ElLAR, D. J. (1982). The role of cortex hydrolysis in the triggering of germination of Bacillus megaterium KM endospores. Biochimica et Biophysica Acta 714, 185-191.
Kawamura, T. \& Shockman, G. D. (1983). Purification and some properties of the endogenous, autolytic $\mathrm{N}$-acetylmuramylhydrolase of Streptococcus faecium, a bacterial glycoenzyme. Journal of Biological Chemistry 258, 9514-9521.

KURODA, A. \& SexiguCHI, J. (1990). Cloning, sequencing and genetic mapping of a Bacillus subtilis cell wall hydrolase gene. Journal of General Microbiology 136, 2209-2216.

LECLERC, D. \& Asselin, A. (1989). Detection of bacterial cell wall hydrolases after denaturing polyacrylamide gel electrophoresis. Canadian Journal of Microbiology 35, 749-753.

Margot, P., Roten, C.-A. H \& Karamata, D. (1991). Labelled cell walls with $\left[{ }^{14} \mathrm{C}\right] \mathrm{L}$-alanine allow sensitive detection of very low activity of $\mathrm{N}$-acetylmuramyl-L-alanine amidase: evidence for an activity in strain carrying flaD2 marker in Bacillus subtilis. Analytical Biochemistry (in the Press).

Marquez, L. M., Helmann, J. D., Ferrari, E., Parker, H. M., ORDAL, G. W. \& ChamberLin, M. J. (1990). Studies of $\sigma^{D}$-dependent functions in Bacillus subtilis. Journal of Bacteriology 172, 3435-3443.

Piggot, P. J. (1989). Revised genetic map of Bacillus subtilis 168. In Regulation of Procaryotic Development, pp. 1-41. Edited by I. Smith, R. A. Slepecky \& P. Setlow. Washington, DC: American Society for Microbiology.

Pooley, H. \& Karamata, D. (1984). Flagellation and the control of autolysin activity in Bacillus subtilis. In Microbial Cell Wall Synthesis and Autolysis, pp. 13-19. Edited by C. Nombela. Amsterdam: Elsevier.

Potvin, C., Leclerc, D., Tremblay, G., Asselin, A. \& Bellemare, G. (1988). Cloning, sequencing and expression of a Bacillus bacteriolytic enzyme in Escherichia coli. Molecular and General Genetics 214, 241-248.

Rogers, H. J., Taylor, C., Rayter, S. \& Ward, J. B. (1984). Purification and properties of autolytic endo- $\beta$ - $N$-acetylglucosaminidase and the $N$-acetylmuramyl-L-alanine amidase from Bacillus subtilis strain 168. Journal of General Microbiology 130, 2395-2402.

SANGer, F., Nicklen, S. \& Coulson, A. R. (1977). DNA sequencing with chain-terminating inhibitors. Proceedings of the National Academy of Sciences of the United States of America 74, 5463-5467.

Stewart, G. S. A. B., Johnstone, K., Hagelberg, E. \& Ellar, D. J. (1981). Commitment of bacterial spores to germinate. Biochemical Journal 198, 101-106.

Thompson, J. S. \& Shockman, G. D. (1968). A modification of the Park and Johnson reducing sugar determination suitable for the assay of insoluble materials. Analytical Biochemistry 22, 260-268.

Tinoco, I., Borer, P. N., Dengler, B., Levine, M. D., Uhlenbeck, O. C., Crothers, D. M. \& Gralla, J. (1973). Improved estimation of secondary structure in ribonucleic acids. Nature, London 246, $40-41$.

TIPPER, D. J. \& GAUTHIER, J. J. (1972). Structure of the bacterial endospore. In Spores V, pp. 3-12. Edited by H. O. Hanson \& L. L. Campbell. Washington, DC: American Society for Microbiology.

Tomasz, A., Moreillon, P. \& PozZI, G. (1988). Insertional inactivation of the major autolysin gene of Streptococcus pneumoniae. Journal of Bacteriology 170, 5931-5934.

W ARD, J. B. \& WILLIAMSON, R. (1984). Bacterial autolysins: specificity and function. In Microbial Cell Wall Synthesis and Autolysis, pp. 159-166. Edited by C. Nombela. Amsterdam: Elsevier.

Youngman, P., Perkins, J. B. \& Losick, R. (1984). Construction of a cloning site near one end of Tn917 into which foreign DNA may be inserted without affecting transposition in Bacillus subtilis or expression of the transposon-borne erm gene. Plasmid 12, 1-9. 